\title{
Tunable Upconversion Luminescence and Energy Transfer Process in $\mathrm{BaLa}_{2} \mathrm{ZnO}_{5}: \mathbf{E r}^{3+} / \mathbf{Y b}^{3+}$ Phosphors
}

\author{
Lefu Mei, Jing Xie, Libing Liao, Ming Guan, and Haikun Liu \\ Beijing Key Laboratory of Materials Utilization of Nonmetallic Minerals and Solid Wastes, National Laboratory of Mineral Materials, \\ School of Materials Science and Technology, China University of Geosciences, Beijing 100083, China
}

Correspondence should be addressed to Lefu Mei; mlf@cugb.edu.cn and Libing Liao; clayl@cugb.edu.cn

Received 17 August 2014; Accepted 29 August 2014

Academic Editor: Zhaohui Li

Copyright (C) 2015 Lefu Mei et al. This is an open access article distributed under the Creative Commons Attribution License, which permits unrestricted use, distribution, and reproduction in any medium, provided the original work is properly cited.

$\mathrm{BaLa}_{2} \mathrm{ZnO}_{5}: \mathrm{Er}^{3+} / \mathrm{Yb}^{3+}$ has been synthesized via a high temperature solid-state method, and the tunable upconversion luminescence and energy transfer process between $\mathrm{Yb}^{3+}$ and $\mathrm{Er}^{3+}$ in this system have been demonstrated. Upon $980 \mathrm{~nm}$ laser excitation, the intense green and red emission around 527, 553, and $664 \mathrm{~nm}$ were observed for $\mathrm{BaLa}_{2} \mathrm{ZnO}_{5}: \mathrm{Er}^{3+} / \mathrm{Yb}^{3+}$, which can be assigned to the characteristic energy level transitions of ${ }^{2} \mathrm{H}_{11 / 2} \rightarrow{ }^{4} \mathrm{I}_{15 / 2},{ }^{4} \mathrm{~S}_{3 / 2} \rightarrow{ }^{4} \mathrm{I}_{15 / 2}$, and ${ }^{4} \mathrm{~F}_{9 / 2} \rightarrow{ }^{4} \mathrm{I}_{15 / 2}$ of Er ${ }^{3+}$, respectively. The critical $\mathrm{Er}^{3+}$ quenching concentration (QC) was determined to be about $5 \mathrm{~mol} \%$, and the power studies indicated that mixture of 2- and 3-photon process was responsible for the green and red upconversion luminescence.

\section{Introduction}

It is believed that the appearance of photon upconversion (UC) luminescence phenomenon has attracted numerous attentions focused on the UC phenomena and UC luminescent materials because of their potential applications in medical labels, multicolor displays [1-4]. The upconversion (UC) luminescence process is achieved through the sequential absorption of two or more excitation photons, which is accorded with the anti-Stokes emission phenomenon. Consequently, UC processes can be induced by low power, continuous wave lasers, obviating the need for high-cost, highintensity pulsed lasers that are required for simultaneous multiphoton absorption experiments such as simultaneous two-photon absorption and second harmonic generation [5, 6]. Up to now, efficient photon UC process has been observed to occur primarily in the rare-earth elements, namely, those of the Ln series. Lanthanide ions are very suitable to be used in UC process as they have the rich energy level structure that allows for efficient spectral conversion. Among all the lanthanides, $\mathrm{Er}^{3+}$ ion has abundant energy level structures, and always acting as the luminescent center can emit intense green and red light. In contrast, $\mathrm{Yb}^{3+}$ ion has a strong and broad near-infrared absorption cross section around $980 \mathrm{~nm}$ with relatively simple electronic structure of two energy level manifolds: ${ }^{2} \mathrm{~F}_{7 / 2}$ ground state and ${ }^{2} \mathrm{~F}_{5 / 2}$ excited state around $10,000 \mathrm{~cm}^{-1}$ in NIR region [7]. Additionally, the similar value of energy level of excited ${ }^{2} \mathrm{~F}_{5 / 2}$ state of $\mathrm{Yb}^{3+}$ is close to the ${ }^{4} \mathrm{I}_{11 / 2}$ levels of $\mathrm{Er}^{3+}$ ions. Accordingly, cooperative UC process has also been reported for $\mathrm{Tm}^{3+} / \mathrm{Yb}^{3+}, \mathrm{Ho}^{3+} / \mathrm{Yb}^{3+}$, and $\mathrm{Tm}^{3+} / \mathrm{Ho}^{3+} / \mathrm{Yb}^{3+}$ couples in many host materials [8-11].

The ternary oxides $\mathrm{XY}_{2} \mathrm{ZO}_{5}(\mathrm{X}=\mathrm{Ba}, \mathrm{Y}=$ rare-earth, and $\mathrm{Z}=\mathrm{Cu}, \mathrm{Zn}$ ) are receiving much attention because of their very interesting structural, excellent physical, and chemical stability and special magnetic, optical, and superconducting properties. As a member of these compounds, $\mathrm{BaY}_{2} \mathrm{ZnO}_{5}$ and $\mathrm{BaGd}_{2} \mathrm{ZnO}_{5}$ have been proved to be efficient UC hosts [12-15]. However, the UC properties of $\mathrm{BaLa}_{2} \mathrm{ZnO}_{5}$ based phosphor have not been investigated. Based on the effective ionic radii and charge balance of cations with different coordination number $(\mathrm{CN})$, the rare-earth $\mathrm{Er}^{3+} / \mathrm{Yb}^{3+}$ ions are expected to occupy the $\mathrm{La}^{3+}$ sites randomly in the $\mathrm{BaLa}_{2} \mathrm{ZnO}_{5}$ host. Therefore, $\mathrm{BaLa}_{2} \mathrm{ZnO}_{5}$ can be an excellent host doped with various ions, and they are promising candidates for practical applications. In this paper, $\mathrm{Er}^{3+} / \mathrm{Yb}^{3+}$ codoped $\mathrm{BaLa}_{2} \mathrm{ZnO}_{5}$ UC materials are synthesized via a solid-state reaction process, and the structure and UC luminescent 


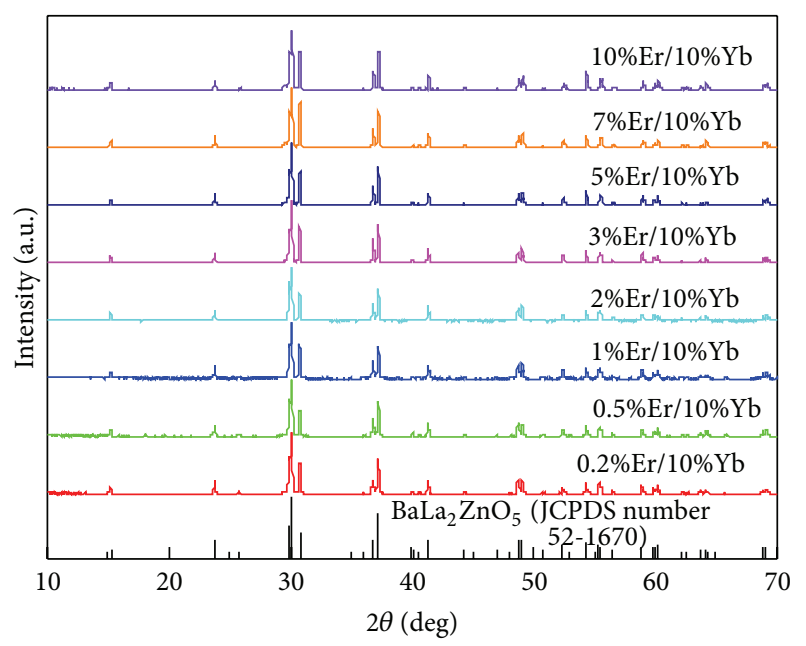

(a)

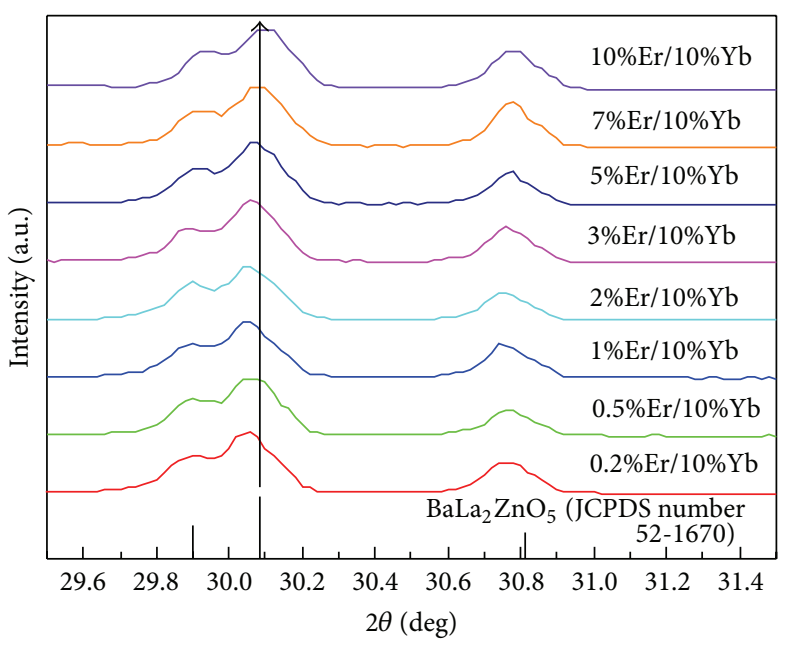

(b)

FIGURE 1: XRD patterns of the $\mathrm{BaLa}_{1.9-x} \mathrm{ZnO}_{5}: x \% \mathrm{Er}^{3+} / 0.10 \mathrm{Yb}^{3+}(x=0.2 \%, 0.5 \%, 1 \%, 2 \%, 3 \%, 4 \%, 5 \%, 7 \%$, and $10 \%)$ and the standard PDF diffraction lines of $\mathrm{BaLa}_{2} \mathrm{ZnO}_{5}$ as a reference: (a) $10^{\circ} \leq 2 \theta \leq 70^{\circ}$ and (b) $29.5^{\circ} \leq 2 \theta \leq 32^{\circ}$.

characteristics of these phosphors have been discussed in detail.

\section{Experimental}

A series of polycrystalline phosphors $\mathrm{BaLa}_{2} \mathrm{ZnO}_{5}: x \mathrm{Er}^{3+} / \mathrm{Yb}^{3+}$ were synthesized by a solid-state reaction technology. The raw materials were $\mathrm{Ba}_{2} \mathrm{CO}_{3}$ (AR), $\mathrm{La}_{2} \mathrm{O}_{3}$ (99.99\%), $\mathrm{ZnO}$ (99.99\%), $\mathrm{Er}_{2} \mathrm{O}_{3}$ (99.99\%), and $\mathrm{Yb}_{2} \mathrm{O}_{3}$ (99.99\%), which were used directly without any treatment. The selected starting materials were mixed and ground thoroughly. The homogeneous mixtures were calcined at $1250^{\circ} \mathrm{C}$ for 3 hours, with the heating rate of $5^{\circ} \mathrm{C} / \mathrm{min}$, and then the samples were cooled to room temperature naturally. After that, the samples were washed three times by the deionized water and dried for the following measurement.

The phase and crystal structure of the samples were recorded by X-ray diffraction (XRD, D8 Advance diffractometer, Bruker Corporation, Germany) with $\mathrm{Cu}$-Ka radiation $(\lambda=0.15406 \mathrm{~nm}, 40 \mathrm{kV}, 30 \mathrm{~mA})$. The morphology of the as-prepared samples was characterized by a field emission scanning electron microscopy (FE-SEM, JSM-7001F). The UC luminescence spectra were recorded on a Hitachi F4600 spectrophotometer (Hitachi High Technologies Corporation, Tokyo, Japan) equipped with an external powercontrollable $980 \mathrm{~nm}$ semiconductor laser (Beijing Viasho Technology Company, China) as the excitation source. All the measurements were carried out at room temperature.

\section{Results and Discussion}

The crystallization and morphology of the as-prepared samples were checked by XRD and SEM measurements. Figure 1 shows the XRD patterns of the $\mathrm{BaLa}_{1.9-x} \mathrm{ZnO}_{5}: x \% \mathrm{Er}^{3+} /$ $0.10 \mathrm{Yb}^{3+}(x=0.2 \%, 0.5 \%, 1 \%, 2 \%, 3 \%, 4 \%, 5 \%, 7 \%$, and $10 \%)$ and the standard PDF diffraction lines of $\mathrm{BaLa}_{2} \mathrm{ZnO}_{5}$ as a reference. It can be seen that all of the diffraction peaks are matched well with the standard data of $\mathrm{BaLa}_{2} \mathrm{ZnO}_{5}$ (JCPDS number 52-1670) indicating the introduction of $\mathrm{Er}^{3+} / \mathrm{Yb}^{3+}$ ions into the $\mathrm{BaLa}_{2} \mathrm{ZnO}_{5}$ lattice is completely dissolved in the $\mathrm{BaLa}_{2} \mathrm{ZnO}_{5}$ host lattice by substitution for the $\mathrm{La}^{3+}$ owing to their similar ionic radii and properties. Moreover, the diffraction peaks of the as-prepared samples shift toward the larger $2 \theta$ side owing to the small size of $\mathrm{Yb}^{3+}$ ion and $\mathrm{Er}^{3+}$ ion substituting for $\mathrm{La}^{3+}$ in the compound.

Figure 2 shows the SEM micrographs of the typical $\mathrm{BaLa}_{2} \mathrm{ZnO}_{5}: 0.05 \mathrm{Er}^{3+} / 0.10 \mathrm{Yb}^{3+}$ powders prepared at $1250^{\circ} \mathrm{C}$ with different plotting scale. SEM result shows sheet-like phosphor grains with an average diameter of about $30 \mu \mathrm{m}$. Compared to the as-prepared samples via high temperature solid-state technology, we can find that the current samples have smooth surface and better crystallinity in the form of two-dimensional flaky states, which indicate that they should own better luminescence properties because of the decreased particle surface defects [16].

Upon the $980 \mathrm{~nm}$ laser excitation, strong visible emission was observed in codoped crystals due to the result of the upconversion process. Figure 3(a) shows the comparison of UC luminescence spectra of the as-prepared $\mathrm{BaLa}_{2} \mathrm{ZnO}_{5}: x \mathrm{Er} / \mathrm{Yb} 10 \%(x=0.2 \%, 0.5 \%, 1 \%, 2 \%, 3 \%, 4 \%$, $5 \%, 7 \%$, and $10 \%)$ samples. The emission consists of two strong bands: the red one peaked at $664 \mathrm{~nm}$ associated with ${ }^{4} \mathrm{~F}_{9 / 2} \rightarrow{ }^{4} \mathrm{I}_{15 / 2}$ transition and the green band centered at $553 \mathrm{~nm}$ assigned to the mixed transition ${ }^{2} \mathrm{H}_{11 / 2}+{ }^{4} \mathrm{~S}_{3 / 2} \rightarrow$ ${ }^{4} \mathrm{I}_{15 / 2}$ of the acceptor $\mathrm{Er}^{3+}$ ion [17]. To date, a wide variety of $\mathrm{Er}^{3+}$ doped $\mathrm{BaLa}_{2} \mathrm{ZnO}_{5}$ have been generated that are capable of emitting a wide range of colors within the visible spectral region. The above result testified the UC process in the $\mathrm{Er}^{3+} / \mathrm{Yb}^{3+}$ doped $\mathrm{BaLa}_{2} \mathrm{ZnO}_{5}$. Additionally, as shown in Figure 3(b), it can be seen that either the green 


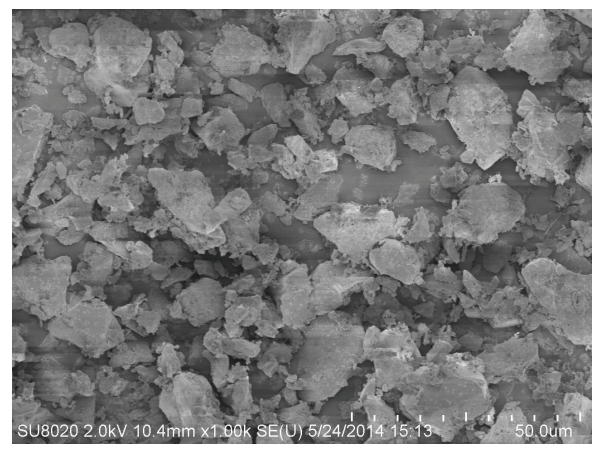

(a)

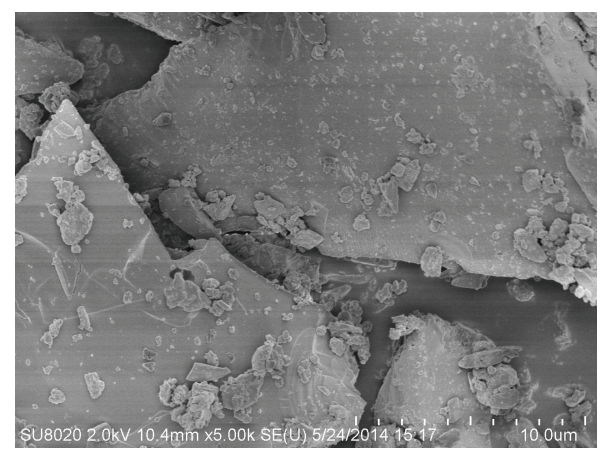

(b)

FIGURE 2: SEM images of the $\mathrm{BaLa}_{2} \mathrm{ZnO}_{5}: 0.05 \mathrm{Er}^{3+} / 0.10 \mathrm{Yb}^{3+}$ plotting scale $\times 1000$ (a) and plotting scale $\times 5000$ (b).

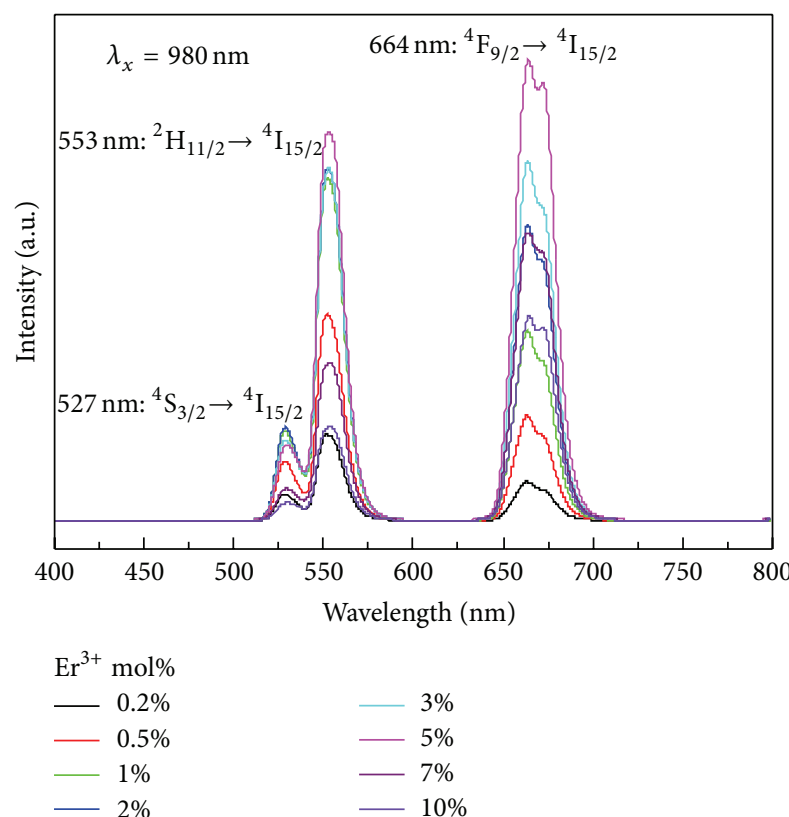

(a)

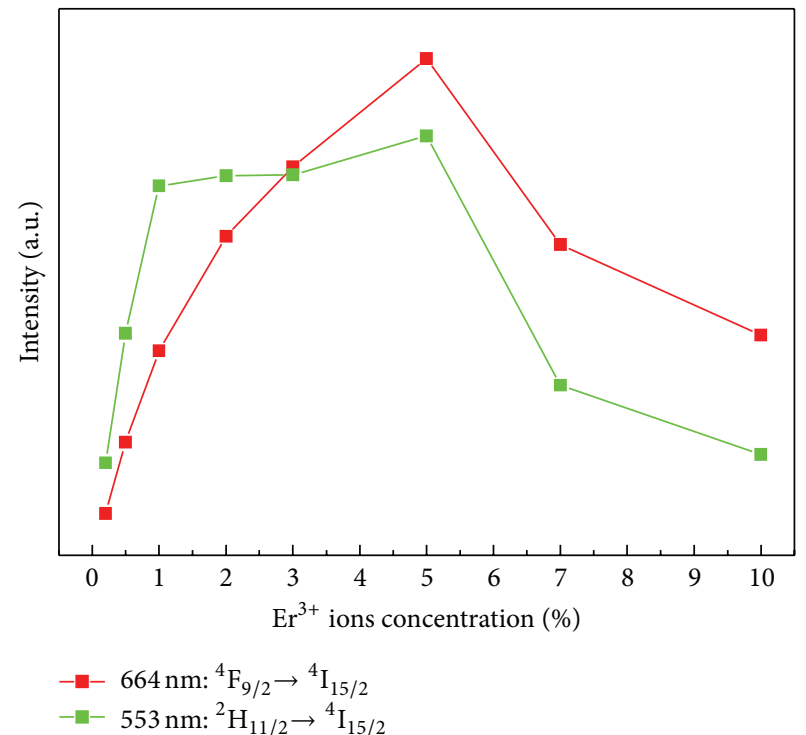

(b)

FIGURE 3: Comparison of UC luminescence spectra of the $\mathrm{BaLa}_{2} \mathrm{ZnO}_{5}: x \mathrm{Er}^{3+} / 0.10 \mathrm{Yb}^{3+}(x=0.2 \%, 0.5 \%, 1 \%, 2 \%, 3 \%, 4 \%, 5 \%, 7 \%$, and $10 \%)$ under $980 \mathrm{~nm}$ laser excitation (a), and the variation of green and red emission intensities corresponds to different $\mathrm{Er}^{3+}$ doping concentration (b).

$(553 \mathrm{~nm})$ or the red $(664 \mathrm{~nm})$ emission band intensities of $\mathrm{BaLa}_{2} \mathrm{ZnO}_{5}: x \mathrm{Er}^{3+} / 10 \% \mathrm{Yb}^{3+}$ increase first and then decrease with the increasing concentration of $\mathrm{Er}^{3+}$ ion, which is attributed to the concentration quenching effect [18]. With increasing the $\mathrm{Er}^{3+}$ contents, the distance between $\mathrm{Er}^{3+}$ and $\mathrm{Yb}^{3+}$ (or $\mathrm{Er}^{3+}$ ) ions decreased to promote nonradiative ET approach and decreased the luminescent intensity of $\mathrm{Er}^{3+}$ ions. After a critical concentration, $5.0 \mathrm{~mol} \%$ of $\mathrm{Er}^{3+}$, both bands are quenched but the intensity of the green one is quenched stronger than that of the red one.

The physical mechanism involved in the upconversion processes can be elucidated by analyzing the dependence of the integrated upconverted intensity $\left(I_{\mathrm{em}}\right)$ as a function of the pumping intensity $\left(P_{\text {pump }}\right)$, which is suggested to obey the following empirical equation [19-21]:

$$
I_{\text {em }} \propto\left(P_{\text {pump }}\right)^{n},
$$

where $n$ is the number of pump photons required for the transition from ground state to the upper emitting state. A plot of $\log I_{\text {em }}$ versus $\log P_{\text {pump }}$ yields a straight line with slope $n$. Figure 4(a) shows the UC emission spectra of $\mathrm{BaLa}_{2} \mathrm{ZnO}_{5}: 5 \% \mathrm{Er}^{3+} / 10 \% \mathrm{Yb}^{3+}$ with different pumping power, and dependence of green and red UC luminescence intensities upon pumping power is shown in Figure 4(b). With the increasing pumping power, UC emission intensities 


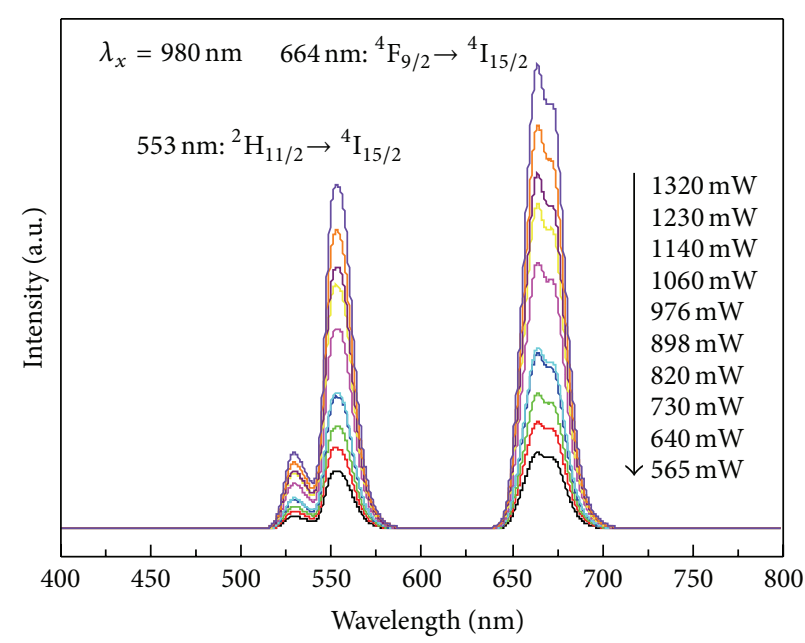

(a)

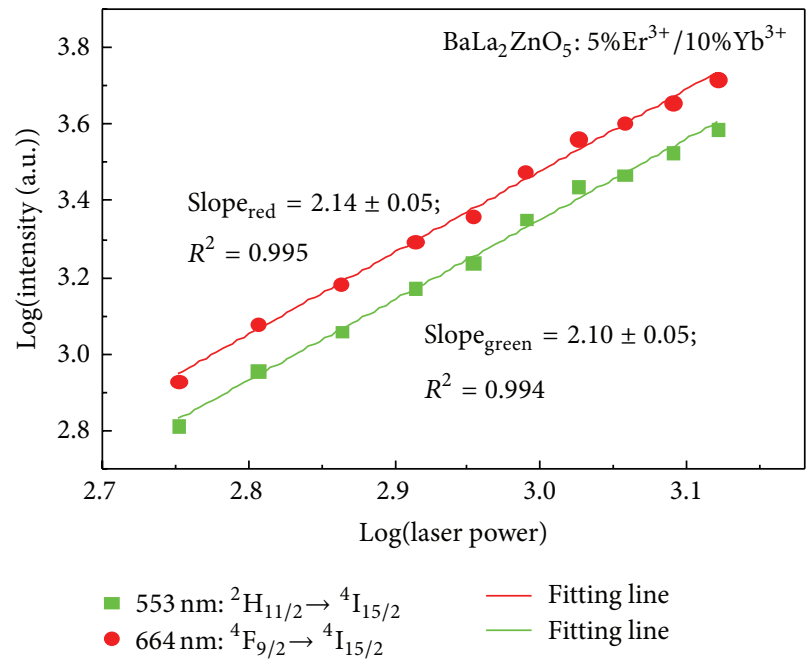

(b)

FIGURE 4: UC emission spectra of $\mathrm{BaLa}_{2} \mathrm{ZnO}_{5}: 0.05 \mathrm{Er}^{3+} / 0.10 \mathrm{Yb}^{3+}$ with different pumping power (a) and dependence of green and red UC emission intensities upon pumping power $(\mathrm{b})$.

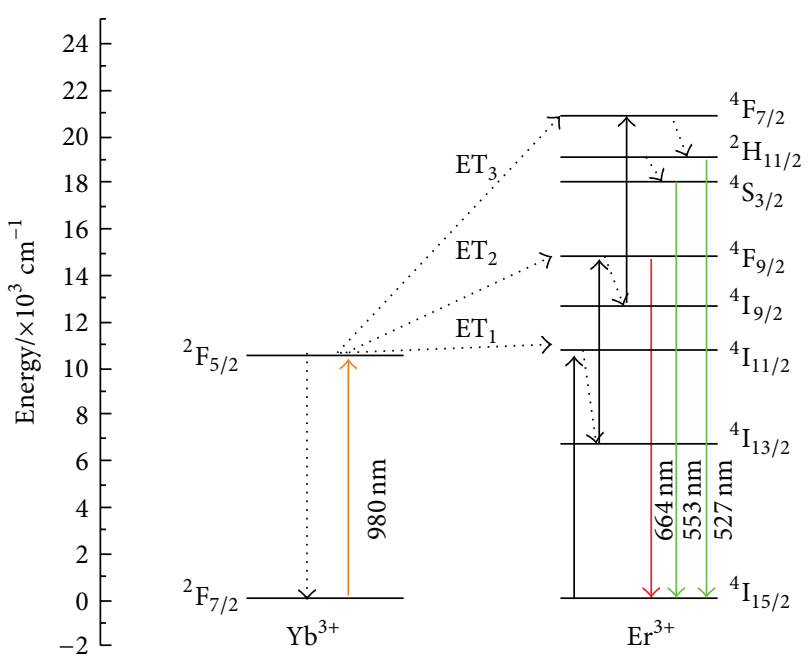

FIgURE 5: Energy level diagram of $\mathrm{Er}^{3+}$ and $\mathrm{Yb}^{3+}$ ions and the proposed UC luminescence mechanisms in $\mathrm{BaLa}_{2} \mathrm{ZnO}_{5}: \mathrm{Er}^{3+} / \mathrm{Yb}^{3+}$.

of $\mathrm{BaLa}_{2} \mathrm{ZnO}_{5}: 5 \% \mathrm{Er}^{3+} / 10 \% \mathrm{Yb}^{3+}$ increased. The calculated slopes were 2.14 for the red emission $\left(664 \mathrm{~nm}:{ }^{4} \mathrm{~F}_{9 / 2} \rightarrow\right.$ ${ }^{4} \mathrm{I}_{15 / 2}$ ) and 2.10 for the green emission $\left(553 \mathrm{~nm}:{ }^{4} \mathrm{~S}_{3 / 2} \rightarrow\right.$

${ }^{4} \mathrm{I}_{15 / 2}$ ), indicating that both red and green emission are the mixture of 2- and 3-photon process which were responsible for the green and red upconversion luminescence. The corresponding energy levels scheme for the infrared excitation and upconversion emission is demonstrated in the schematic energy level diagram of $\mathrm{Er}^{3+}$ and $\mathrm{Yb}^{3+}$ ions, as shown in Figure 5. According to the above-mentioned threephoton process in $\mathrm{BaLa}_{2} \mathrm{ZnO}_{5}: \mathrm{Er}^{3+} / \mathrm{Yb}^{3+}$, the $\mathrm{Yb}^{3+}$ ions act as sensitizer and the $\mathrm{Er}^{3+}$ ions as activators. Under $980 \mathrm{~nm}$

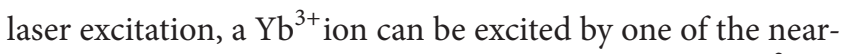
infrared photons and transited from the ground state of ${ }^{2} \mathrm{~F}_{7 / 2}$ to the only excited state of ${ }^{2} \mathrm{~F}_{5 / 2}$ and then transfers the energy to $\mathrm{Er}^{3+}$ ion and promotes the transition of ${ }^{4} \mathrm{I}_{15 / 2} \rightarrow{ }^{4} \mathrm{I}_{11 / 2}$ of $\mathrm{Er}^{3+}$ ion. Furthermore, $\mathrm{Er}^{3+}$ in ${ }^{4} \mathrm{I}_{11 / 2}$ level is easy to reach a lower excited level of ${ }^{4} \mathrm{I}_{13 / 2}$ by a nonradiative relaxation as the similar value of energy level. Then, the second step of $\mathrm{ET}_{2}$ from $\mathrm{Yb}^{3+}$ can promote an excited state absorption (ESA) of $\mathrm{Er}^{3+}$ from ${ }^{4} \mathrm{I}_{13 / 2}$ to the ${ }^{4} \mathrm{~F}_{9 / 2}$ level. In this case, the emission band located in the red region which associated with the transition of ${ }^{4} \mathrm{~F}_{9 / 2} \rightarrow{ }^{4} \mathrm{I}_{15 / 2}$. The third energy transfer step $\left(\mathrm{ET}_{3}\right)$ are followed as: $\mathrm{Er}^{3+}$ ions at ${ }^{4} \mathrm{~F}_{9 / 2}$ level relax nonradiatively again and back to another lower excited level of ${ }^{4} \mathrm{I}_{9 / 2}$, and then the $\mathrm{Er}^{3+}$ are excited from ${ }^{4} \mathrm{I}_{9 / 2}$ to ${ }^{4} \mathrm{~F}_{7 / 2}$ by another ESA process. In this case, the emission band located in the green region which associated with the ${ }^{2} \mathrm{H}_{11 / 2} \rightarrow{ }^{4} \mathrm{I}_{15 / 2}$ and ${ }^{4} \mathrm{~S}_{3 / 2} \rightarrow{ }^{4} \mathrm{I}_{15 / 2}$ transitions of $\mathrm{Er}^{3+}$ ions, respectively. Accordingly, green emission concerted at 527 and $549 \mathrm{~nm}$ was detected in the UC spectra.

\section{Conclusions}

UC phosphors of $\mathrm{Er}^{3+} / \mathrm{Yb}^{3+}$ codoped $\mathrm{BaLa}_{2} \mathrm{ZnO}_{5}$ were synthesized by a traditional solid-state reaction method. Under $980 \mathrm{~nm}$ near-infrared laser excitation, both green $(527 \mathrm{~nm}$ and $553 \mathrm{~nm})$ and red $(664 \mathrm{~nm})$ emission bands have been found in the UC spectra, and these emission peaks are assigned to the characteristic level transition of ${ }^{2} \mathrm{H}_{11 / 2} \rightarrow{ }^{4} \mathrm{I}_{15 / 2},{ }^{4} \mathrm{~S}_{3 / 2} \rightarrow{ }^{4} \mathrm{I}_{15 / 2}$, and ${ }^{4} \mathrm{~F}_{9 / 2} \rightarrow{ }^{4} \mathrm{I}_{15 / 2}$ of $\mathrm{Er}^{3+}$, respectively. The influence of $\mathrm{Er}^{3+}$ doped concentration on UC luminescence intensities has been studied, which 
depicts that the optimum $\mathrm{Er}^{3+}$ doped concentration is $5 \%$. The dependence of the UC luminescence on pumping power indicates that the energy transfer from $\mathrm{Yb}^{3+}$ to $\mathrm{Er}^{3+}$ in the $\mathrm{BaLa}_{2} \mathrm{ZnO}_{5}$ host is a three-photon process. The mechanisms for the green and red UC luminescence were discussed in detail.

\section{Conflict of Interests}

The authors declare that there is no conflict of interests regarding the publication of this paper.

\section{Acknowledgments}

This present work was supported by the National Natural Science Foundations of China (Grant nos. 51202226, 41172053, and 51172216), the Fundamental Research Funds for the Central Universities (Grant nos. 2652013043 and 2652013128), Science and Technology Innovation Fund of the China University of Geosciences (Beijing), and the Fundamental Research Funds for the Central Universities (53200959276).

\section{References}

[1] S. Das, A. A. Reddy, S. S. Babu, and G. V. Prakash, “Tunable visible upconversion emission in $\mathrm{Er}^{3+} / \mathrm{Yb}^{3+}$-codoped $\mathrm{KCaBO}_{3}$ phosphors by introducing $\mathrm{Ho}^{3+}$ ions," Materials Letters, vol. 120 , pp. 232-235, 2014.

[2] G. Y. Chen, H. L. Qiu, P. N. Prasad, and X. Y. Chen, "Upconversion nanoparticles: design, nanochemistry, and applications in theranostics," Chemical Reviews, vol. 114, pp. 5161-5214, 2014.

[3] H. K. Liu, Y. Y. Zhang, L. B. Liao, Q. F. Guo, and L. F. Mei, "Synthesis, broad-band absorption and luminescence properties of blue-emitting phosphor $\mathrm{Sr}_{8} \mathrm{La}_{2}\left(\mathrm{PO}_{4}\right)_{6} \mathrm{O}_{2}: \mathrm{Eu}^{2+}$ for n-UV whitelight-emitting diodes," Ceramics International, vol. 40, no. 8, pp. 13709-13713, 2014.

[4] J. Zhang, Y. Wang, L. Guo, and P. Dong, "Up-conversion luminescence and near-infrared quantum cutting in $\mathrm{Y}_{6} \mathrm{O}_{5} \mathrm{~F}_{8}: \mathrm{RE}^{3+}$ $(\mathrm{RE}=\mathrm{Yb}, \mathrm{Er}$, and $\mathrm{Ho})$ with controllable morphologies by hydrothermal synthesis," Dalton Transactions, vol. 42, no. 10, pp. 3542-3551, 2013.

[5] F. Auzel, "Upconversion and anti-stokes processes with $\mathrm{f}$ and d ions in solids," Chemical Reviews, vol. 104, no. 1, pp. 139-173, 2004.

[6] M. V. DaCosta, S. Doughan, Y. Han, and U. J. Krull, "Lanthanide upconversion nanoparticles and applications in bioassays and bioimaging: a review," Analytica Chimica Acta, vol. 832, pp. 133, 2014.

[7] M. Guan, L. F. Mei, Z. H. Huang, C. X. Yang, Q. F. Guo, and Z. G. Xia, "Synthesis and near-infrared luminescence properties of LaOCl: $\mathrm{Nd}^{3+} / \mathrm{Yb}^{3+}$," Infrared Physics \& Technology, vol. 60, pp. 98-102, 2013.

[8] W. Zheng, H. Zhu, R. Li et al., "Visible-to-infrared quantum cutting by phonon-assisted energy transfer in $\mathrm{YPO}_{4}: \mathrm{Tm}^{3+}, \mathrm{Yb}^{3+}$ phosphors," Physical Chemistry Chemical Physics, vol. 14, no. 19, pp. 6974-6980, 2012.

[9] J. Y. Sun, B. Xue, G. C. Sun, and D. P. Cui, "Yellow upconversion luminescence in $\mathrm{Ho}^{3+} / \mathrm{Yb}^{3+}$ co-doped $\mathrm{Gd}_{2} \mathrm{Mo}_{3} \mathrm{O}_{9}$ phosphor," Journal of Rare Earths, vol. 31, no. 8, pp. 741-744, 2013.
[10] J. Sun, B. Xue, and H. Du, "White upconverted luminescence of $\mathrm{Ho}^{3+} / \mathrm{Yb}^{3+} / \mathrm{Tm}^{3+}$ tri-doped $\mathrm{Gd}_{2} \mathrm{Mo}_{3} \mathrm{O}_{9}$ phosphors," Materials Science and Engineering B: Solid-State Materials for Advanced Technology, vol. 178, no. 12, pp. 822-825, 2013.

[11] Z. Xia, W. Zhou, H. Du, and J. Sun, "Synthesis and spectral analysis of $\mathrm{Yb}^{3+} / \mathrm{Tm}^{3+} / \mathrm{Ho}^{3+}$-doped $\mathrm{Na}_{0.5} \mathrm{Gd}_{0.5} \mathrm{WO}_{4}$ phosphor to achieve white upconversion luminescence," Materials Research Bulletin, vol. 45, no. 9, pp. 1199-1202, 2010.

[12] I. Etchart, I. Hernández, A. Huignard et al., "Efficient oxide phosphors for light upconversion; green emission from $\mathrm{Yb}^{3+}$ and $\mathrm{Ho}^{3+}$ co-doped $\mathrm{Ln}_{2} \mathrm{BaZnO}_{5}(\mathrm{Ln}=\mathrm{Y}, \mathrm{Gd})$," Journal of Materials Chemistry, vol. 21, no. 5, pp. 1387-1394, 2011.

[13] C. Guo, J. Yu, J.-H. Jeong, Z. Ren, and J. Bai, "Effect of $\mathrm{Eu}^{3+}$ contents on the structure and properties of $\mathrm{BaLa}_{2} \mathrm{ZnO}_{5}: \mathrm{Eu}^{3+}$ phosphors," Physica B: Condensed Matter, vol. 406, no. 4, pp. 916-920, 2011.

[14] G. Y. Dong, C. C. Hou, Z. P. Yang et al., "Color-tunable, single phased $\mathrm{BaLa}_{2-x-y} \mathrm{ZnO}_{5}: \mathrm{xBi}^{3+}, \mathrm{yEu}^{3+}$ phosphors with efficient energy transfer under ultraviolet excitation," Ceramics International, vol. 40, pp. 14787-14792, 2014.

[15] I. Etchart, M. Berard, M. Laroche et al., "Efficient white light emission by upconversion in $\mathrm{Yb}^{3+}-, \mathrm{Er}^{3+}$ - and $\mathrm{Tm}^{3+}$-doped $\mathrm{Y}_{2} \mathrm{BaZnO}_{5}$," Chemical Communications, vol. 47, no. 22, pp. 6263-6265, 2011.

[16] Z. G. Xia, J. Li, Y. Luo, and L. B. Liao, "Comparative investigation of green and red upconversion luminescence in $\mathrm{Er}^{3+}$ doped and $\mathrm{Yb}^{3+} / \mathrm{Er}^{3+}$ Codoped LaOCl," Journal of the American Ceramic Society, vol. 95, no. 10, pp. 3229-3234, 2012.

[17] T. Li, C. F. Guo, Y. R. Wu, L. li, and J. H. Jeong, "Green upconversion luminescence in $\mathrm{Yb}^{3+} / \mathrm{Er}^{3+} \mathrm{co}$-doped $\mathrm{ALn}\left(\mathrm{MoO}_{4}\right)_{2}(\mathrm{~A}=\mathrm{Li}$, $\mathrm{Na}$ and $\mathrm{K} ; \mathrm{Ln}=\mathrm{La}, \mathrm{Gd}$ and Y)," Journal of Alloys and Compounds, vol. 540, pp. 107-112, 2012.

[18] B. P. Singh, A. K. Parchur, R. K. Singh, A. A. Ansari, P. Singh, and S. B. Rai, "Structural and up-conversion properties of $\mathrm{Er}^{3+}$ and $\mathrm{Yb}^{3+}$ co-doped $\mathrm{Y}_{2} \mathrm{Ti}_{2} \mathrm{O}_{7}$ phosphors," Physical Chemistry Chemical Physics, vol. 15, no. 10, pp. 3480-3489, 2013.

[19] Y. C. Yang, C. Mi, F. Yu et al., "Optical thermometry based on the upconversion fluorescence from $\mathrm{Yb}^{3+} / \mathrm{Er}^{3+}$ codoped $\mathrm{La}_{2} \mathrm{O}_{2} \mathrm{~S}$ phosphor," Ceram. Inter, vol. 40, no. 7, pp. 9875-9880, 2014.

[20] P. Du, Z. Xia, and L. Liao, "Tunable upconversion luminescence and energy transfer process between $\mathrm{Yb}^{3+}$ and $\mathrm{Er}^{3+}$ in the $\mathrm{CaY}_{4} \mathrm{~F}_{14}$," Journal of Luminescence, vol. 133, pp. 226-229, 2013.

[21] Y. F. Jiang, R. S. Shen, X. P. Li et al., "Concentration effects on the upconversion luminescence in $\mathrm{Ho}^{3+} / \mathrm{Yb}^{3+}$ co-doped $\mathrm{NaGdTiO}_{4}$ phosphor," Ceramics International, vol. 38, no. 6, pp. 5045-5051, 2012. 

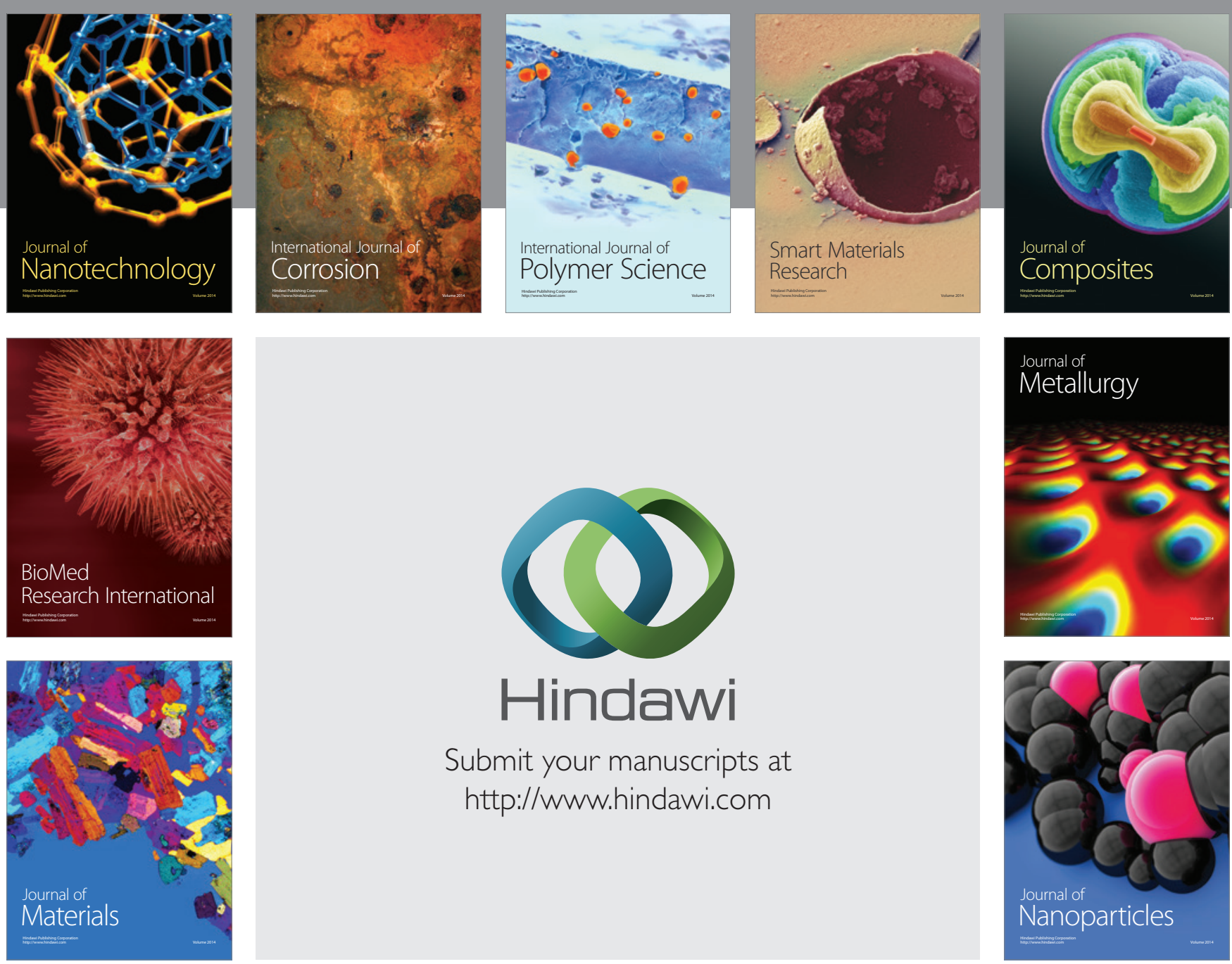

Submit your manuscripts at http://www.hindawi.com
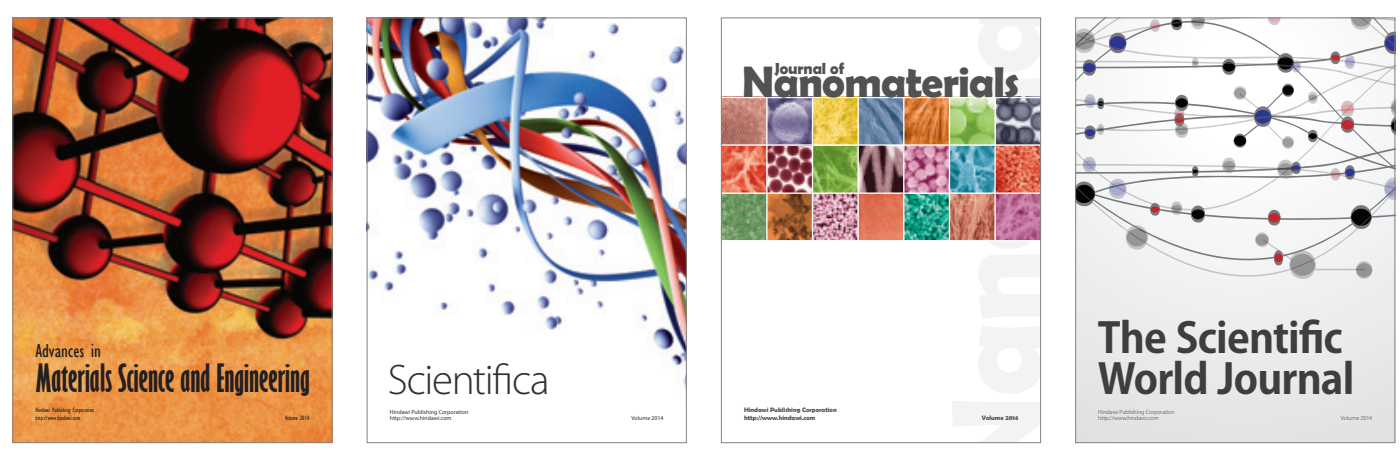

\section{The Scientific World Journal}
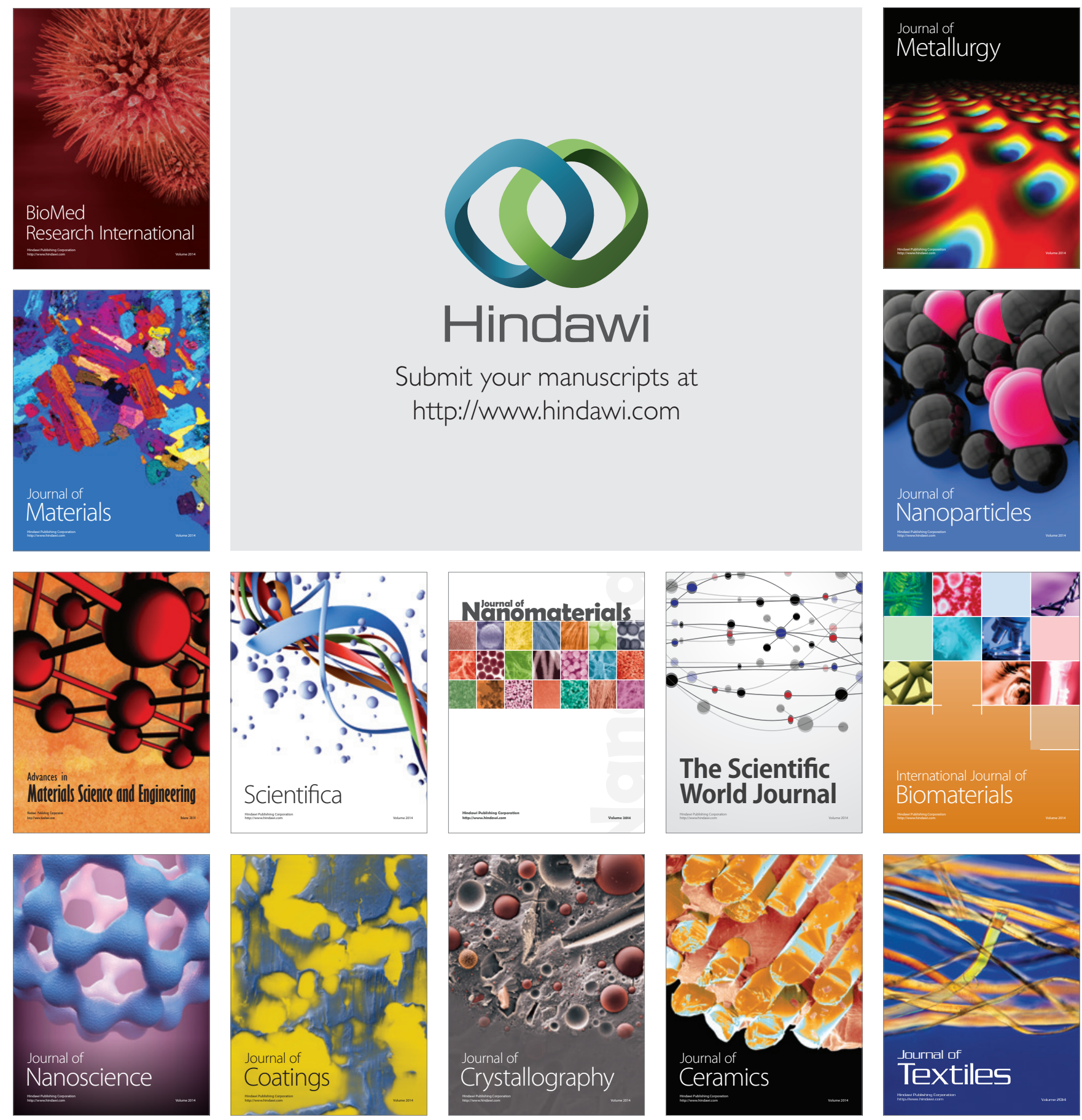